\title{
In Vitro Effect of Indomethacin on Polymorphonuclear Leukocyte Function in Preterm Infants
}

\author{
SHAHID KAMRAN, SHAISTA S. USMANI, RAUL A. WAPNIR, RAJEEV MEHTA, AND \\ RITA G. HARPER \\ Department of Pediatrics, Division of Perinatal Medicine, and the Department of Obstetrics-Gynecology, North \\ Shore University Hospital-Cornell University Medical College, Manhasset, New York 11030
}

\begin{abstract}
Random motility and chemotaxis of polymorphonuclear leukocytes (PMN) was evaluated after in vitro exposure to $0,300,600$, and $900 \mathrm{ng} / \mathrm{mL}(0.84,1.68$, and $2.52 \mu \mathrm{mol} / \mathrm{L}$ ) of indomethacin. PMN were obtained from cord blood of 22 preterm infants of less than $37 \mathrm{wk}$ gestation. For comparison, PMN were obtained from cord blood of seven healthy full-term infants and from venous blood of 10 normal adults. In preterm infants, a significant decrease of random motility and chemotaxis of PMN was noted at all three drug concentrations; impairment of PMN function was dose dependent in the three groups $(p<$ $0.0001)$, with the greatest effect seen at $900 \mathrm{ng} / \mathrm{mL}(2.52$ $\mu \mathrm{mol} / \mathrm{L}$ ). Significant impairment of random motility was noted in full-term infants when compared with adults at all indomethacin concentrations and in chemotaxis at 300 and $600 \mathrm{ng} / \mathrm{mL}(0.84$ and $1.68 \mu \mathrm{mol} / \mathrm{L})$. The study indicates that indomethacin has an adverse effect on PMN random motility and chemotaxis, which is more pronounced in preterm infants. (Pediatr Res 33: 32-35, 1993)
\end{abstract}

\section{Abbreviations}

PDA, patent ductus arteriosus

PMN, polymorphonuclear leukocyte

HBSS, Hanks' balanced salt solution

Indomethacin is accepted therapy to achieve closure of the PDA in preterm infants (1). Bacterial infections are a major cause of morbidity and mortality in newborn infants, particularly preterm infants (2). The high incidence of sepsis in the neonate appears to be secondary to the immaturity of the immune system (3). Defects in antibody-mediated immunity and abnormal function of PMN are the two major proposed mechanisms by which the risk of bacterial infection is increased. It has been shown that during the neonatal period PMN from stable, preterm infants demonstrate significantly decreased random motility and chemotaxis when compared with PMN from healthy, term neonates and adults (4).

Indomethacin is commonly used in the first $2 \mathrm{wk}$ of life, a time when the rate of septicemia in the newborn is highest $(1-3$, 5). Indomethacin has been shown to alter the PMN function in human and animal models, but conflicting reports have been published by different authors (6-9). The objective of this study was to determine if random motility or chemotaxis of PMN in

Received June 24, 1992; accepted September 8, 1992.

Correspondence and reprint requests: Rita G. Harper, M.D., Chief, Division of Perinatal Medicine, North Shore University Hospital, 300 Community Drive, Manhasset, NY 11030

${ }^{1}$ Presented in part at the 1992 FASEB meeting, Anaheim, CA. preterm infants is altered by in vitro exposure to concentrations of indomethacin similar to that of plasma after indomethacin therapy. We also examined whether PMN from full-term infants and adults would similarly show alterations in random motility or chemotaxis.

\section{SUBJECTS AND METHODS}

Subjects. The study subjects consisted of three groups. Group I comprised 22 preterm infants (gestational age $32.5 \pm 3.1 \mathrm{wk}$; birth weight $1884 \pm 659 \mathrm{~g}$ ) born at North Shore University Hospital from September to December 1991. There were equal numbers of males and females. Fourteen were born by cesarean section and eight by normal vaginal delivery. Because each infant served as his or her own control, infants with a history of maternal drug intake were included in the study. Four mothers were given magnesium sulfate and two received ritodrine for tocolysis before delivery. Two mothers received betamethasone for lung maturation within $24 \mathrm{~h}$ of delivery. One mother was on digoxin and furosemide for congestive heart failure.

Group II comprised seven full-term, healthy neonates (gestational age $39.1 \pm 1.2 \mathrm{wk}$; birth weight $3230 \pm 161 \mathrm{~g}$ ) born at North Shore University Hospital during the same period. There were three males and four females. Two were born by cesarean section and five by normal vaginal delivery. There was no history of drug intake in any of the mothers. Group III comprised 10 healthy adult volunteers. None of the volunteers was on any medication.

The study was approved by the Institutional Research and Publications Review Committee on human subjects at North Shore University Hospital. Informed consent is not required by the North Shore University Hospital Institutional Research and Publications Review Committee for obtaining cord blood from human subjects.

$P M N$ function studies. For preterm and term infants, cord blood was obtained in the delivery room from the veins of the fetal side of the placenta after the placenta was extracted. Blood was obtained using an 18-gauge needle and a $10-\mathrm{mL}$ plastic syringe. Blood was heparinized with 10 units $/ \mathrm{mL}$ of heparin after collection. From adults, a venous sample was obtained and heparinized as above. PMN function studies were commenced within half an hour of collection.

PMN were separated according to the method of Boyum (10) and washed twice in HBSS without $\mathrm{Ca}, \mathrm{Mg}$, and phenol red. The cells were adjusted to a concentration of $10 \times 10^{6} \mathrm{PMN} / \mathrm{mL}$ in HBSS. One-half $\mathrm{mL}$ of cell suspension $\left(5 \times 10^{6}\right.$ cells $)$ was added to each of four plastic tubes. In tube 1 , which served as a control, $1.5 \mathrm{~mL}$ of HBSS was added. In tubes 2, 3, and 4, indomethacin as the sodium salt (Indocin i.v., Merck, Sharp, and Dohme, West Point, PA) was added to a final concentration of 300,600 , and $900 \mathrm{ng} / \mathrm{mL}(0.84,1.68$, and $2.52 \mu \mathrm{mol} / \mathrm{L})$, respectively. Total 
volume of fluid was adjusted to $2 \mathrm{~mL}$ by adding HBSS to these tubes. The tubes were then incubated with gentle shaking in a $37^{\circ} \mathrm{C}$ water bath for $30 \mathrm{~min}$. The cells were washed again with HBSS before motility assays were performed. The cells were adjusted to a concentration of $2 \times 10^{6} \mathrm{PMN} / \mathrm{mL}$ in $2 \%$ BSA for random motility and chemotaxis. After separation, cell suspension contained $>85 \%$ PMN and trypan blue dye exclusion showed $>95 \%$ PMN viability.

Random motility and chemotaxis were tested by a modified Boyden technique with the use of blind-well chambers (NeuroProbe, Inc., Bethesda, MD) and $5 \mu \mathrm{m}$ pore cellulose nitrate filters (Millipore Corp., Bedford, MA) (11). Pooled human serum activated by Zymosan (Sigma Chemical Co., St. Louis, MO) was used as a chemoattractant. Tissue culture medium-199 (Gibco Laboratories, Grand Island, NY) was used to determine random motility. Samples were tested in duplicates after incubation of cells for $2 \mathrm{~h}$ at $37^{\circ} \mathrm{C}$. Random motility and chemotaxis were expressed as the mean depth in $\mu \mathrm{m}$ at which the leading front of PMN was in focus using a $\times 40$ objective. Mean value represents the average of readings in five randomly chosen microscopic fields in each filter.

Statistical analysis. Repeated measures analysis of variance was used to evaluate all data. The data obtained with zero drug concentration (control) were compared with those obtained with 300,600 , and $900 \mathrm{ng} / \mathrm{mL}(0.84,1.68$, and $2.52 \mu \mathrm{mol} / \mathrm{L})$ indomethacin.

To determine the intergroup differences, multiple comparisons (Tukey's studentized range test) was performed. A value less than or equal to 0.05 was considered the significance threshold (12).

\section{RESULTS}

In preterm infants, $<37 \mathrm{wk}$ gestation, a significant impairment of random motility of PMN was noted in comparison to the values obtained in full-term infants and adults (Fig. 1). These differences were observed in the absence of indomethacin but were more pronounced at all three drug concentrations used. At all concentrations of indomethacin, random motility in full-term infants was significantly lower than that of adults (Fig. 1). A significant dosage effect $(p<0.0001)$ was found in the three groups, with impairment of random motility increasing with increased doses of indomethacin.

There was also a very significant reduction in the chemotaxis of PMN from preterm infants as compared with that of full-term infants and adults in the absence of indomethacin and at all concentrations. Chemotaxis values of full-term infants were lower at 300 and $600 \mathrm{ng} / \mathrm{mL}(0.84$ and $1.68 \mu \mathrm{mol} / \mathrm{L})$ than those of adults (Fig. 2). In chemotaxis, as well as in random motility, impairment of the three groups to graded indomethacin concentrations was observed and was significant at the $p<0.0001$ level.

The relative effect of indomethacin in vitro on random motility was greater in the PMN of preterm infants than in the PMN of full-term infants and adults at 600 and $900 \mathrm{ng} / \mathrm{mL}(1.68$ and $2.52 \mu \mathrm{mol} / \mathrm{L}$ ) (Fig. 3). This difference was particularly apparent at the highest concentration. At all concentrations, relative values of full-term and adult PMN were indistinguishable. Similarly, relative chemotaxis was more affected in the preterm PMN than in the PMN of full-term infants and adults at 600 and $900 \mathrm{ng} /$ $\mathrm{mL}$ (1.68 and $2.52 \mu \mathrm{mol} / \mathrm{L}$ ) (Fig. 4).

\section{DISCUSSION}

In this study, indomethacin was found to impair PMN random motility and chemotaxis in preterm as well as full-term infants and adults (Figs. 1 and 2). In preterm infants, a concentration of only $300 \mathrm{ng} / \mathrm{mL}(0.84 \mu \mathrm{mol} / \mathrm{L})$ of indomethacin produced a very significant decline of both random motility and chemotaxis. This effect was not observed, however, in the PMN of either fullterm infants or adults. The impairment in motility was progressive with increasing concentration in the three groups. It was consistently more pronounced at a concentration of $900 \mathrm{ng} / \mathrm{mL}$ $(2.52 \mu \mathrm{mol} / \mathrm{L})$, a level usually achieved in the plasma of preterm infants after a single dose of $0.2-0.3 \mathrm{mg} / \mathrm{kg}(0.55-0.83 \mu \mathrm{mol} / \mathrm{kg})$ indomethacin administered during the first week of life (13).

The results also indicate that the PMN of preterm infants have greater sensitivity to indomethacin than the PMN of the two other groups (Figs. 3 and 4). The lower doses of indomethacin (300 and $600 \mathrm{ng} / \mathrm{mL}$ ) $(0.84$ and $1.68 \mu \mathrm{mol} / \mathrm{L})$, which elicited significant decline in random motility and chemotaxis in preterm infants, had no effect on the PMN of adults. Only starting at 600 $\mathrm{ng} / \mathrm{mL}(1.68 \mu \mathrm{mol} / \mathrm{L})$ was there a reduction of the two parameters in the PMN of full-term infants.

PMN function has been shown to be affected by antiinflammatory drugs, including indomethacin (6-9). Possible impairment of PMN function has been extensively studied in animals. Controversial results have been reported by various investigators

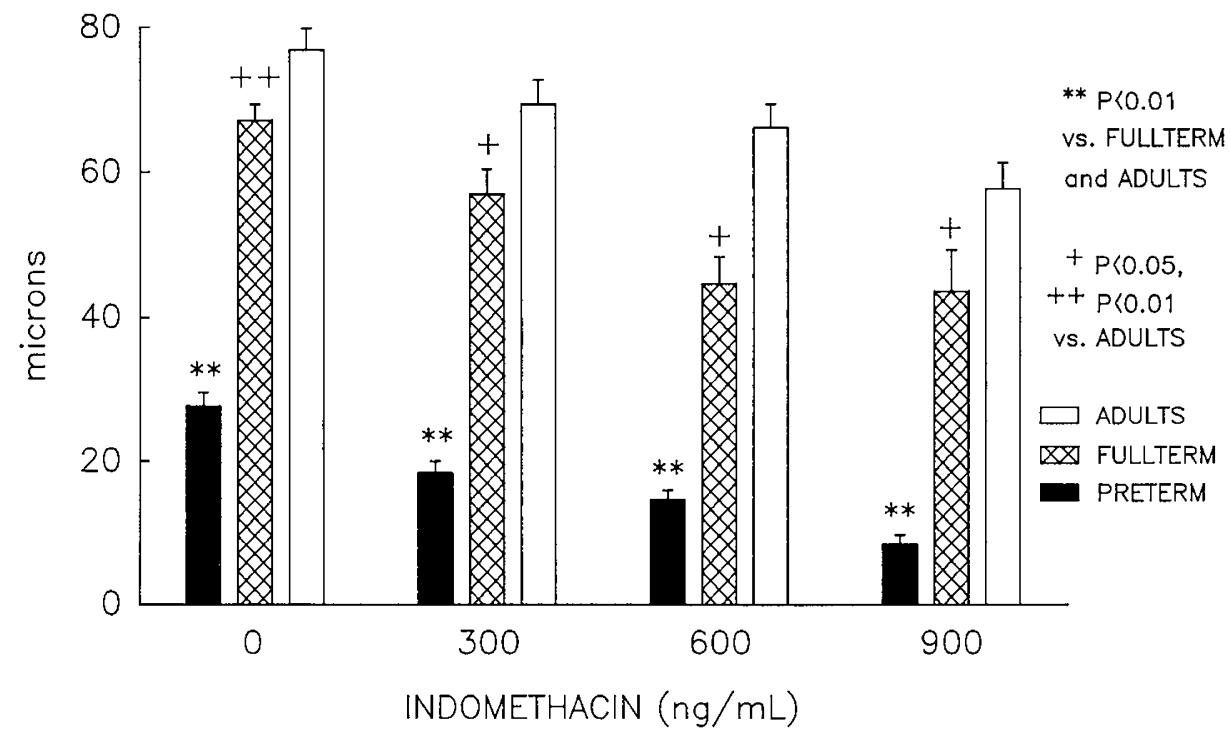

Fig. 1. Comparison of random motility of PMN of preterm and full-term infants and adults as a function of indomethacin concentration in vitro. The random motility of preterm infant leukocytes was consistently lower than that of the other two groups' PMN. The values of full-term PMN were also lower than those of adults at all indomethacin concentrations $(300 \mathrm{ng} / \mathrm{mL}=0.84 \mu \mathrm{mol} / \mathrm{L} ; 600 \mathrm{ng} / \mathrm{mL}=1.68 \mu \mathrm{mol} / \mathrm{L} ; 900 \mathrm{ng} / \mathrm{mL}$ $=2.52 \mu \mathrm{mol} / \mathrm{L})$. The error bars denote the SEM. For preterm infants, $n=22$; full-term infants, $n=10$; adults, $n=7$. 


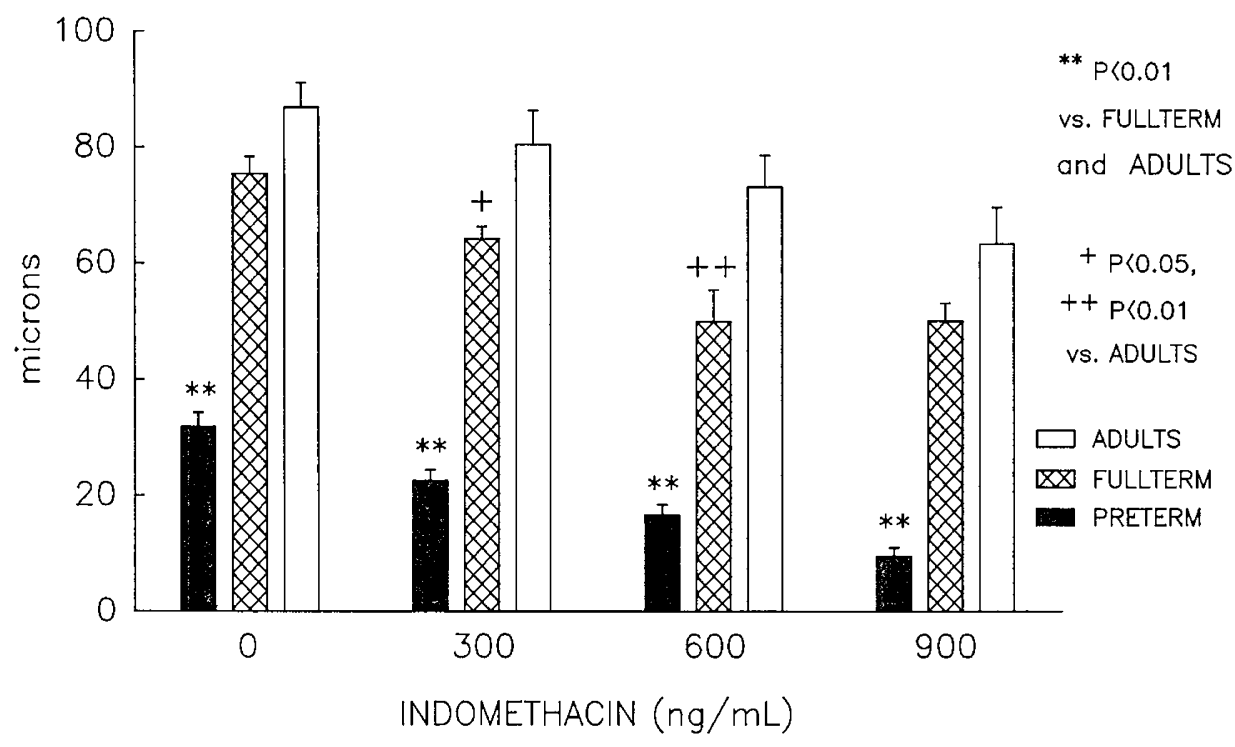

Fig. 2. Chemotactic activity of PMN of preterm and full-term infants and adults. Chemotaxis of preterm PMN was lower than that of full-term infants and adults at two concentrations. Other features of the graph are the same as in Figure 1.

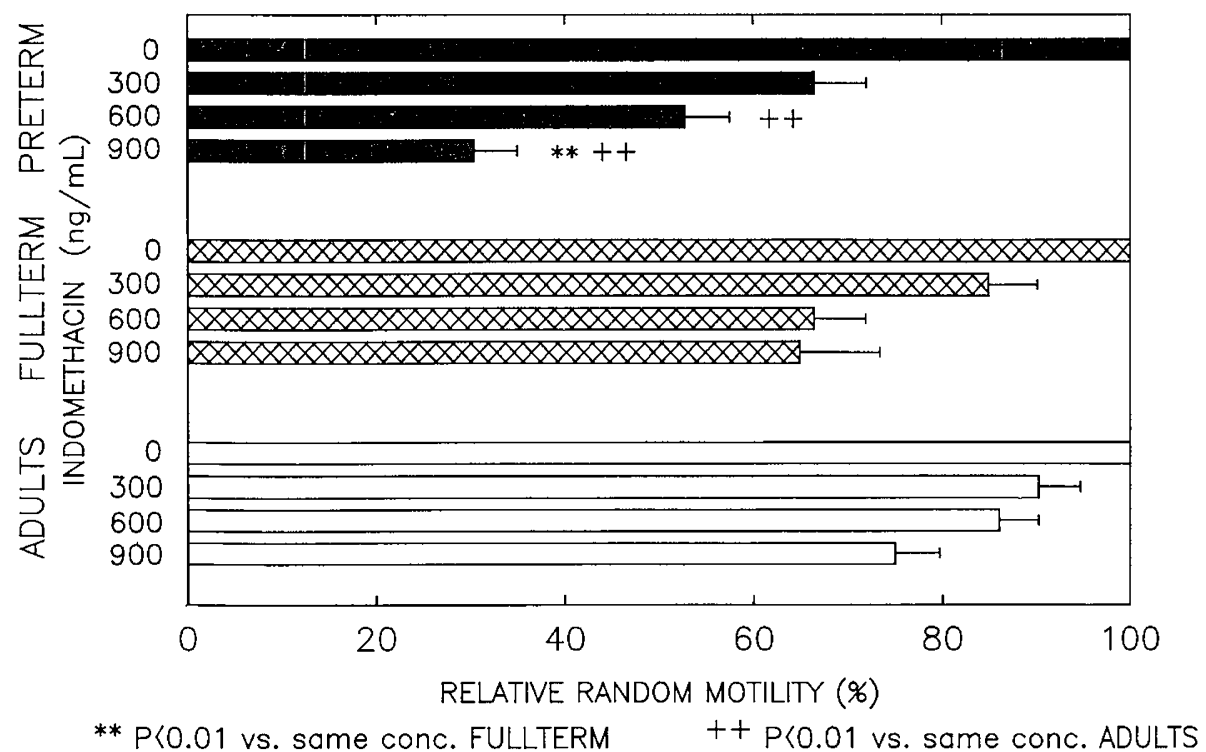

Fig. 3. Relative random motility of PMN of preterm and full-term infants and adults in the presence of indomethacin in vitro. The reduction of random motility in the PMN of preterm infants was significantly different from that of full-term infants only at $900 \mathrm{ng} / \mathrm{mL}(2.52 \mu \mathrm{mol} / \mathrm{L})$, but it was more pronounced than that of adult PMN at 600 and $900 \mathrm{ng} / \mathrm{mL}(1.68$ and $2.52 \mu \mathrm{mol} / \mathrm{L})$. Other characteristics of data presentation are as in Figure 1.

in different animal species. Indomethacin was able to reduce chemotactic activity of inflammatory exudates for both PMN and monocytes in Wistar rats (14). This effect was postulated to be due to reduced plasma kininogen levels and prostaglandins. Similarly, other investigators have reported lower random and directed motility of PMN at the inflammatory site; this impairment was noted to be dose dependent and due to inhibition of PMN cyclooxygenase activity $(7,15)$. However, in another study, no inhibition of PMN accumulation and motility was noted when indomethacin was placed on nitrocellulose discs implanted subcutaneously into mice (16).

In human adults, a dose-dependent inhibition of superoxide generation has been reported in PMN that were preincubated with indomethacin (8). This inhibition was seen at indomethacin concentrations approximating plasma and tissue levels obtained in adults at usual therapeutic doses. Similarly, preincubation of adult PMN in vitro with indomethacin resulted in an inhibition of formyl-methionyl-leucyl-phenylalanine-induced aggregation of PMN, but had no effect on superoxide generation (17).
In the neonatal literature, to our knowledge, there is only one other study on the effect of indomethacin on PMN function. No difference was found in PMN chemotaxis and adherence before, and 2 to $4 \mathrm{~h}$ after, oral indomethacin administration in nine preterm infants (18). However, in a retrospective chart review, the same authors noted a significant increase in the incidence of sepsis in a group of preterm infants treated with oral indomethacin for PDA when compared with infants treated with surgery or usual medical management. The negative results of that paper (18) stand in contrast to previous studies in adults that indicated abnormalities in PMN function induced by indomethacin (8-9, 18 ) as well as to the results obtained in our study. Moreover, the greater sensitivity of the preterm infants' PMN to indomethacin observed in our study is suggestive of an increased susceptibility of the preterm infant's immune system to the adverse effects of indomethacin as compared with full-term infants and adults.

In summary, the in vitro findings of significant reduction of PMN function by doses of indomethacin easily attainable during 


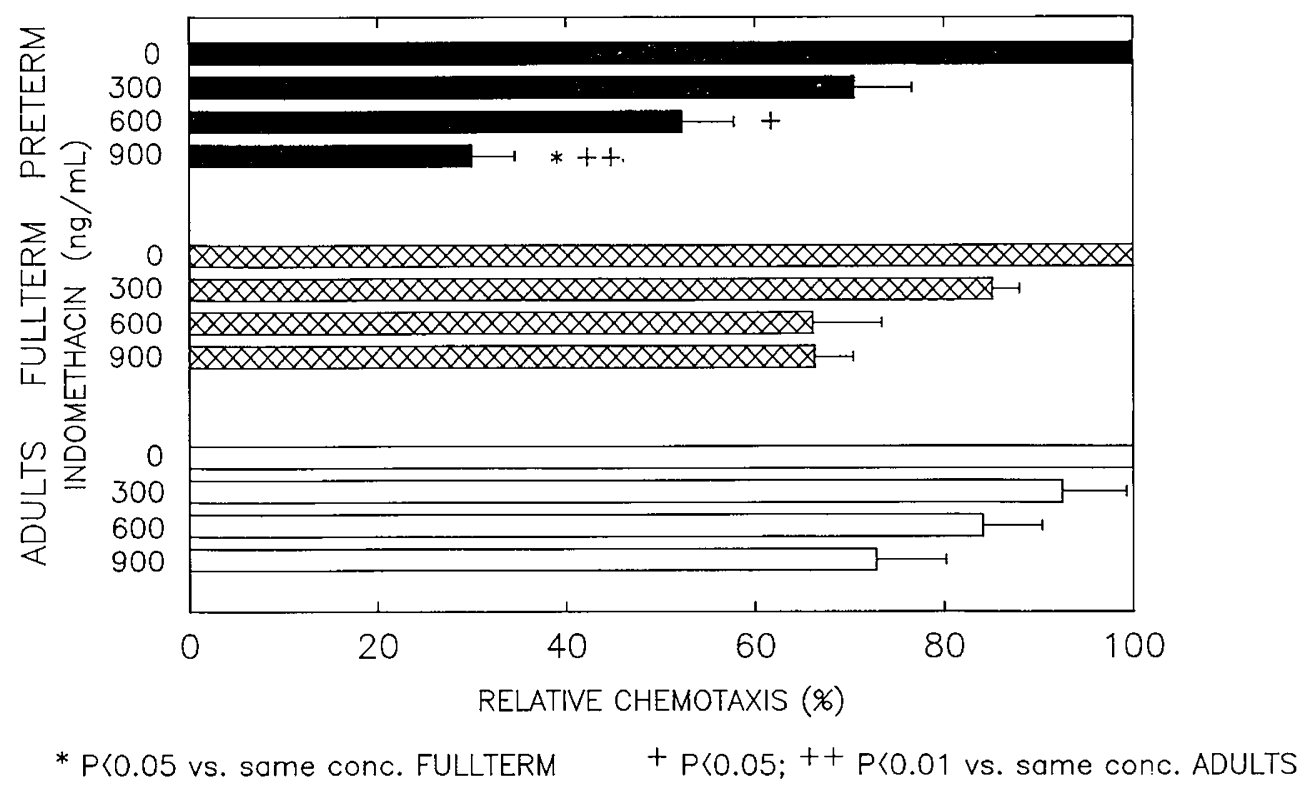

Fig. 4. Relative alteration of PMN chemotaxis of preterm and full-term infants and adults by indomethacin in vitro. The proportional reduction in chemotaxis was greater in preterm than in full-term infants only at the highest concentration but was greater than that of adults at 600 and 900 $\mathrm{ng} / \mathrm{mL}(1.68$ and $2.52 \mu \mathrm{mol} / \mathrm{L})$. Number of patients and data presentation are as in the other figures.

therapy used to close the PDA call for caution before use. Further in vivo studies are needed to determine whether PMN function is altered during indomethacin therapy in the preterm infants and, if so, for what time period and to what extent.

\section{REFERENCES}

1. McCarthy JS, Zies LG, Gelband H 1978 Age-dependent closure of patent ductus arteriosus by indomethacin. Pediatrics 62:706-712

2. Vesikari T, Janas P, Gronroos P, Tuppurainen N, Renlund M, Kero P, Koivisto M, Kumas M, Heinonen K, Nyman R, Pettay O, Osterlund K 1985 Neonatal septicemia. Arch Dis Child 60:542-546

3. Boxer LA 1978 Immunologic function and leukocyte disorders in newborn infants. Clin Hematol 7:123-146

4. Usmani SS, Schlessel JS, Sia CG, Kamran S, Orner SD 1991 Polymorphonuclear leukocyte function in the preterm neonate: effect of chronologic age. Pediatrics 87:675-679

5. Miller ME 1979 Phagocytic function in the neonate: selected aspects. Pediatrics 64:709-712

6. Parente L, Koh MS, Willoughby DA, Kitchen A 1979 Studies on cell motility in inflammation II. The in vivo effect of anti-inflammatory and anti-rheumatic drugs on chemotaxis in vitro. Agents Actions 9:196-200

7. Perianin A, Giroud JP, Hakin J 1988 Differential in vivo effects of indomethacin, ibuprofen, and flurbiprofen on oxygen-dependent killing activities of neutrophils elicited by acute nonimmune inflammatory in the rat. Inflammation 12:181-189
8. Simchowitz L, Mehta J, Spilberg I 1979 Chemotactic factor-induced generation of superoxide radicals by human neutrophils. Arthritis Rheum 22:755-762

9. Panus PC, Longenecker GL, Jones HP, Chartrand SA, Peevy KJ 1987 In vitro inhibition of group B streptococcus-induced polymorphonuclear leukocyte aggregation. Inflammation 11:111-115

10. Boyum A 1968 Separation of leukocytes from blood and bone marrow. Scand J Clin Lab Invest 21:7-12

11. Smith W, Hollers JC, Patrick RA, Hassett C 1979 Motility and adhesiveness in human neutrophils: effects of chemotactic factors. J Clin Invest 63:221229

12. Zar JH 1984 Biostatistical Analysis, 2nd Ed. Prentice-Hall, Englewood Cliffs, $\mathrm{NJ}$

13. Yaffe SJ, Friedman WF, Rogers D, Lang P, Ragni M, Saccar C 1980 The disposition of indomethacin in preterm babies. J Pediatr 97:1001-1006

14. Perianin A, Roch Arveiller M, Giroud JP, Hakim J 1985 In vivo effects of indomethacin and flurbiprofen on the locomotion of neutrophils elicited by immune and non-immune inflammation in the rat. Eur $J$ Pharmacol 106:327-333

15. Myers RF, Anthes JC, Casmer CJ, Siegel MI 1985 Ex vivo effects of nonsteroidal anti-inflammatory drugs on arachinonic acid metabolism in neutrophils from a reverse passive arthus reaction. Inflammation 9:91-98

16. Green AP, Mangan FR 1983 The effect of anti-inflammatory and antirheumatic drugs on cell accumulation onto nitrocellulose discs implanted subcutaneously into mice. Agents Actions 13:368-372

17. Abramson S, Edelson H, Kaplan H, Given W, Weissmann G 1984 The inactivation of the polymorphonuclear leukocyte by non-steroidal antiinflammatory drugs. Inflammation 8:S103-S108

18. Herson VC, Krause PJ, Eisenfeld LI, Pontius L, Maderazo EG 1988 Indomethacin-associated sepsis in very low birthweight infants. Am $J$ Dis Child 142:555-558 